\title{
AS VÍTIMAS DA VIOLÊNCIA: ENTRE DISCURSOS CIENTÍFICOS E BIOPOLÍTICAS DO CONTEMPORÂNEO
}

VÍCTIMAS DE LA VIOLENCIA: MIENTRE DISCURSOS CIENTÍFICOS Y LAS BIOPOLÍTICAS CONTEMPORÁNEAS

VICTIMS OF VIOLENCE: BETWEEN SCIENTIFIC DISCOURSES AND BIOPOLITICS OF CONTEMPORARY

Carlos Eduardo Nórte

Universidade Federal do Rio de Janeiro, Rio de Janeiro/RJ, Brasil

\section{RESUMO}

Este artigo apresenta reflexões em torno do papel social da vítima da violência na produção do medo e da insegurança, e sua influência no aumento dos mecanismos repressivos do estado penal brasileiro. Foi realizada uma pesquisa bibliográfica não sistemática buscando proposições acerca da criação de uma psicopatologia relacionada à vitimização, nesse caso o Transtorno de Estresse Pós-Traumático (TEPT). Indo além de uma proposta de caracterização do transtorno em si, o presente trabalho teve como objetivo entender as práticas que o engendram, quais contingências históricas o fizeram emergir em um determinado momento e quais efeitos têm produzido na medicalização da vida e nas atuais políticas públicas de segurança de nossa sociedade.

Palavras-chave: Transtorno de Estresse Pós-Traumático; medicalização; violência; criminalização; políticas públicas.

\section{RESUMEN}

Este artículo presenta una reflexión sobre el papel social de las víctimas de la violencia en la génesis del miedo y la sensación de inseguridad, así como su influencia en el aumento de los mecanismos represivos del Estado penal brasileño. Se realizó una búsqueda no sistemática en la literatura sobre las propuestas de la creación de una psicopatología relacionada con la victimización, en este caso el Trastorno de Estrés Postraumático (TEPT). Más allá de una propuesta de caracterización del trastorno en sí, el objetivo de este estudio fue comprender las prácticas que lo causan, así como las contingencias históricas que lo hicieron surgir en un momento determinado y los efectos que han producido en la medicalización de la población y en las políticas públicas de seguridad de nuestra sociedad.

Palabras clave: Trastorno de Estrés Postraumático; medicalización; violencia; criminalización; políticas públicas.

\begin{abstract}
This article presents some reflections about the social role of violence victims in the production of fear and insecurity and its influences in the repressive mechanisms in state criminal justice. We performed a systematic literature search seeking proposals about the creation of a psychopathology related to victimhood, the Posttraumatic Stress Disorder (PTSD). More than a simple characterization of the disorder, our aim was to investigate the practices that engender it, which public historical contingencies emerged at a given time and what effects are produced in the medicalization of life and current public security policies.
\end{abstract}

Keywords: Posttraumatic Stress Disorder; medicalization; violence; criminalization; public policy 


\section{Introdução}

A exposição a situações de risco de morte e seus impactos na saúde física e mental atravessam toda a história da humanidade, variando nos mais diversos contextos, culturas e sociedades. Atualmente, os discursos proferidos sobre situações de guerra, pessoas que sofreram tortura, sequestros, desastres naturais, assaltos, acidentes de trânsito, até as mais íntimas situações, tais como a morte de alguém querido, violência doméstica contra a mulher e/ou contra crianças e bebês são compreendidos clínica e metaforicamente como situações "traumáticas". O uso de uma única palavra (trauma) para representar uma pluralidade de significados, contextos e interpretações potencialmente coloca sobre a mesma égide singularidades que nos fazem pensar nos efeitos sociais que determinadas palavras colocam na leitura de fatos e eventos.

Com o advento do Manual Diagnóstico e Estatístico para Transtornos Mentais da American Psychiatry Association e a criação do Transtorno de Estresse Pós-Traumático, o conceito de trauma e a legitimação de uma psicopatologia relacionada a ele têm proporcionado uma grande ampliação dos diagnósticos e uma verdadeira epidemia de pessoas ditas traumatizadas. Por conta disso, psicólogos e diversos outros profissionais da saúde são cada vez mais incitados a trabalhar com esse tema tão delicado em seus mais diversos campos de atuação, tendo que realizar diagnósticos, pareceres, intervenções e emitir opiniões públicas sobre pessoas traumatizadas, suas sequelas emocionais e seus efeitos sociais. Entretanto, apesar da vasta literatura sobre os aspectos psicológicos relacionados a experiências traumáticas, que variam desde os estudos de Sigmund Freud até os recentes achados de neuroimagem, pouco vem sendo discutido sobre o papel social e os usos conferidos a um diagnóstico de doença mental relacionado a experiências traumáticas na vitimização das pessoas e no direcionamento de políticas públicas.

O objetivo do presente trabalho é produzir reflexões em torno do papel social da vítima da violência, e de que modo, ao ser apropriado pelo discurso médico, pode influenciar na manutenção do medo e da insegurança, e consequentemente no aumento dos mecanismos repressivos do estado penal brasileiro. Em especial, buscamos enunciar como a criação nosológica de um índice psicopatológico, o Transtorno do Estresse Pós-Traumático, pode estar relacionado a fatores econômicos, políticos e sociais, que não se remetem exclusivamente à promoção de saúde naqueles que sofrem o impacto da violência em sua saúde mental. Para esse fim, foi realizada uma pesquisa bibliográfica não sistemática de artigos nas bases Scielo, Pubmed e Isi Web of Knowledge, além da busca de livros e outros materiais (tais como reportagens e entrevistas) com o intuito de colher informações em que fosse possível examinar, através de uma perspectiva genealógica (Foucault, 1988), os principais usos das palavras "trauma", "vítima da violência", "segurança pública" e "estresse póstraumático" e compreender os mecanismos de poder sobre os sujeitos na criação de diagnósticos, as formas de medicalização das vítimas de violência e a relação dessa temática com as atuais políticas de segurança pública.

\section{A vítima da violência e a psicopatologia em questão}

No Brasil, segundo Reichenheim et al. (2011), no ano de 2007 a maior causa de mortes provocadas por fatores externos está relacionada aos índices de homicídio $(36,4 \%)$ e ao trânsito $(29,3 \%)$. A taxa de homicídios é superior à de outros países como China, Argentina, África do Sul e Colômbia. Além disso, o estudo constatou que os homens têm dez vezes mais chances de morrer por homicídio do que as mulheres e que, em sua maioria, são homens jovens, negros, na faixa entre 15 a 29 anos e com baixa escolaridade. Em 2004, a violência custou mais de 87 bilhões de reais, sendo que para o setor público foram gastos 28 bilhões. Já o Sistema Único de Saúde (SUS) gastou cerca de R\$ 114 milhões em admissões em hospitais decorrentes de assaltos, que em grande parte se relacionavam a tentativas de homicídio. Perversamente, as altas taxas de homicídio e a difusão do medo e da insegurança também alimentam outra parte da economia, na qual se observa o aumento de $74 \%$ do número de companhias de segurança privada entre os anos de 1997 e 2007 (Reichenheim et al., 2011). Tais dados indicam a existência de um mercado altamente lucrativo associado com as taxas de homicídios e difusão do medo e da insegurança na população.

Um estudo epidemiológico realizado na cidade de São Paulo por Andrade et al. (2012) aponta que a experiência de ter vivido um evento traumático relacionado à violência urbana foi presente em cerca de $54,6 \%$ da amostra. O estudo também apontou que a quantidade de exposição a situações de violência também está relacionada com um aumento significativo de sofrimento psíquico dos sujeitos acometidos por tais eventos. Tais números sugerem que a violência tem provocado sequelas não apenas físicas, mas também mentais na população brasileira, em que o 
transtorno de estresse pós-traumático representa uma das marcas mais expoentes dos efeitos da violência na saúde mental.

Segundo o DSM-IV, Manual Diagnóstico e Estatístico para Transtornos Mentais (American Psychiatric Association, 1994), o Transtorno do Estresse Pós-Traumático (TEPT) é caracterizado por uma reação de medo intenso, impotência ou horror quando o indivíduo vivencia, testemunha ou toma conhecimento de morte ou ferimentos graves (critério A para diagnóstico). Ainda de acordo com o manual, os sintomas devem causar sofrimento clinicamente significativo, prejuízo social ou em outras áreas importantes do funcionamento, devendo iniciar até os seis primeiros meses após o evento e ter duração superior a um mês. O TEPT é diagnosticado quando o indivíduo, além do critério A, apresenta um sintoma de revivescência (critério B: lembranças intrusivas, pesadelos traumáticos, flashbacks, sofrimento psíquico evocado por estímulos relacionados ao trauma, reatividade fisiológica evocada por estímulos relacionados ao trauma), três sintomas de comportamento evitativo/entorpecimento emocional (critério C: esforço para evitar pensamentos e sentimentos associados com o trauma; esforço para evitar atividades, locais ou pessoas associadas com o trauma; redução do interesse nas atividades; sensação de distanciamento em relação a outras pessoas; restrição da expressão afetiva, entorpecimento emocional; sentimento de um futuro abreviado), e dois sintomas de hiperexitabilidade (critério D: hipervigilância, insônia, resposta de sobressalto exagerada, irritabilidade, dificuldade em se concentrar).

O que a nosologia do TEPT tem de singular e a diferencia de qualquer outro transtorno é o seu agente etiológico. Assume-se uma postura essencialista em que o diagnóstico repousa em algo que (regra geral) aconteceu num passado relativamente remoto. Um acontecimento "fora do espectro da experiência humana usual". A fenomenologia desse transtorno considera sobretudo as ações humanas e as suas implicações traumáticas, assentando na noção de que há memórias que são traumáticas - mentes feridas, fragmentadas por um evento violento que deixou indeléveis marcas, que constantemente reaparecem de forma espontânea, onde o sujeito revê ao longo de sua vida as dramáticas e dolorosas inscrições mentais de seu próprio sofrimento experienciado no passado. Essa nosologia moralizante veiculada pelos discursos da psiquiatria moderna utiliza-se de uma matriz vocabular pautada em elementos do passado de forma a reconstituir uma parte de uma história biográfica (desconsiderando os outros fatores pessoais, sociopolíticos e econômicos que podem influenciar nessa experiência) para justificar e estabelecer uma causalidade com o presente vivido.

Alguns estudos sugerem que os sintomas de estresse pós-traumático aparecem naturalmente na maior parte da população nos dias e semanas posteriores à exposição a uma situação traumática, e são considerados como efeito de uma resposta comum e adaptativa frente a um estímulo estressor que ameace a integridade física ou mental do indivíduo (McFarlane, 2000). O trabalho desenvolvido por Kessler, Sonnega, Bromet, Hughes e Nelson (1995) aponta que a maior parte das pessoas expostas a situações traumáticas não desenvolvem o transtorno, e mesmo entre os sujeitos que desenvolveram TEPT (aqueles que mantiveram os sintomas por um período superior a um mês) a trajetória comum é a remissão espontânea dos sintomas com um forte declínio ocorrendo nos três primeiros meses após o trauma. Portanto, de acordo com esses pesquisadores, o TEPT pode ser compreendido como uma falha nos mecanismos de recuperação natural e uma sustentação crônica dos sintomas após a exposição a um evento traumático, que impede a restituição do equilíbrio físico e mental do indivíduo.

Recentemente, um grupo de pesquisadores investigou a frequência anual de publicação dos transtornos de ansiedade em um período de 10 anos (Dugas, Anderson, Deschenes, \& Donegan, 2010). Em seus resultados, o aumento vertiginoso de publicações relacionadas ao TEPT e o interesse da comunidade científica em torno desse tema é o que mais chama a atenção. Tais dados indicam que o TEPT apresentou quase o dobro de publicações (cerca de 8147) durante esses 10 anos em comparação a outros transtornos, tais como Transtorno Obssessivo Compulsivo e Transtorno do Pânico (que apresentaram apenas 4813 e 1252 publicações respectivamente). Já Boschen (2008) afirma que o TEPT é o transtorno de ansiedade mais estudado desde 1980, e que até 2015 continuará a ser um tema de grande destaque dentro do cenário mundial.

Afinal, o que podemos pensar a partir desses números? Quais relações podem ser feitas a respeito dos índices de violência, número de vítimas e o aumento progressivo de estudos em torno do Transtorno de Estresse Pós-Traumático? Quais razões que colocam o TEPT atualmente em evidência? Será que os outros transtornos perderam a importância ao longo dos últimos anos? Esses questionamentos nos fazem ainda perguntar sobre quais sujeitos são produzidos a partir dessas relações de saber e de poder, e como isso reverbera em nossa sociedade.

O termo medicalização da vida vem sendo utilizado para compreender o modo como determinados 
modos de vida vêm sendo gradativamente analisados em termos médicos, onde certas condutas e formas singulares de existir sofrem a passível análise de normalidade a partir de uma ótica moral ou estritamente biológica, gerando "conflitos acerca do estatuto médico, social, epistêmico ou ontológico de determinadas doenças e, portanto, da necessidade de controle e terapêutica das mesmas" (Gaudenzi \& Ortega, 2011, p. 22).

Para entender melhor a medicalização das vítimas de violência e seus efeitos sociais é preciso mudar o ângulo de visão para novas e desnaturalizantes percepções da realidade para que seja possível entender como categorias são construídas e utilizadas. Representações não apenas descrevem realidades, mas também as transformam, e também certas práticas não apenas seguem um conhecimento a priori mas o justificam em retrospecto. Busca-se, portanto, não se prender necessariamente em descobrir se o trauma é real ou qual é o melhor tratamento para esse sofrimento, mas ao invés disso buscamos entender quais efeitos a leitura da violência sob a ótica do trauma reverbera em nossa sociedade, especialmente na esfera moral das regras, normas e condutas que modulam nossas formas de ser, agir e pensar no mundo.

Se seguirmos a assertiva foucaultiana de que o saber está inseparavelmente entrelaçado ao exercício do poder institucional nas socidades modernas, podemos compreender como determinados discursos, ao receberem o status de verdade, produzem efeitos no mundo, onde produções de conhecimento não se resumem a um projeto epistemológico, mas também a questões políticas, econômicas e sociais. Portanto, o importante é pensar como o domínio saber-poder isola determinado objeto como alvo, e o faz suscetível a determinadas formas de saber, imobilizando-o em uma rotina de práticas. A categoria de objeto erroneamente pode implicar uma forma de existência estática, independente e a-histórica, que pode ser facilmente desvinculada de um determinado tempo, lugar e contexto social. Assim, o objeto corre o risco de se tornar um objeto de explicaçâo transcedental.

Portanto, precisa-se desnaturalizar determinadas práticas e objetos em suas explicações transcedentais e pensá-los no contexto sociopolítico em que foram produzidos. Logo, faz-se necessário recorrer ao passado para buscarmos os processos históricos que instituíram o Transtorno de Estresse Pós-Traumático como um potencial aspecto nosológico que caracteriza o sofrimento mental em pessoas expostas a risco de vida.

De acordo com Summerfield (2001), o diagnóstico de TEPT é um legado da guerra americana no Vietnã e um produto dos infortúnios produzidos pelo pós-guerra. Após a Guerra do Vietnã, os soldados americanos foram severamente acusados de serem assassinos cruéis e sanguinários pelo povo americano, que acompanhava na televisão as atrocidades realizadas contra civis vietnamitas. $\mathrm{O}$ autor relata que a dificuldade de os soldados retornarem e se ajustarem novamente ao país de origem foi associada a sintomas de ansiedade, depressão, uso de substâncias tóxicas e transtornos de personalidade. Tais diagnósticos foram subtituídos pelo que posteriormente seria chamado de Transtorno de Estresse Pós-Traumático.

O novo diagnóstico representou uma mudança no modo pelo qual os soldados passaram a ser reconhecidos pela sociedade. Houve uma forte transformação política: os veteranos do Vietnã deixaram de ser torturadores e assassinos e passaram a ser vistos como pessoas traumatizadas pelo exercício militar experienciado durante a guerra. O Transtorno de Estresse PósTraumático promoveu uma vitimização dos soldados vindos da guerra e legitimou uma desculpa moral em resposta às críticas advindas da população, além de garantir auxílio financeiro a aqueles disgnosticados como incapacitados a continuar com a carreira militar devido ao novo transtorno (Young, 1995).

O Transtorno de Estresse Pós-Traumático, que originalmente foi aplicado a condições extremas que fogem do cotidiano, tais como situações de guerra, ganhou no DSM-IV uma ampliação dos eventos considerados traumáticos, entre eles os acidentes automobilísticos, abuso sexual, dificuldades de trabalho, assalto, sequestro, receber notícias ruins e perda de pessoas queridas. Partindo da perspectiva de que a angústia e o desconforto após um evento estressante passaram a ser entendidas como uma condição psiquiátrica, pode-se imaginar o perigo quando sujeitos saudáveis podem ser considerados vítimas a serem medicalizadas, em um processo que individualiza as questões do cotidiano e desconsidera os contextos sociopolíticos nos quais os sujeitos estão inseridos. Nesse sentido, De Jong K, Mulhern, Ford, Van der Kam e Kleber (2000) ilustram em seu estudo como o poder psiquiátrico de produção de diagnósticos pode levar à medicalização excessiva e a psiquiatrização em massa de uma população. $\mathrm{O}$ autor descreveu um estudo randomizado com cerca 245 adultos expostos a situações estressantes na Guerra da Serra Leoa, ao qual diagnosticou nada menos que 99\% da amostra com Transtorno de Estresse PósTraumático.

A partir de tais achados, coloca-se em evidência os perigos do uso inadequado do discurso médico, e a sua tentativa de utilização como um instrumento de 
normalização e normatização social, que engrendra processos de medicalização das práticas cotidianas. O biopoder, descrito por Michel Foucault (1988), concede à ciência a função de normalizadora da sociedade, criando assim anormalidades a serem tratadas e reformadas em prol de um desenvolvimento econômico. Esse poder que se encarrega de gerir a vida precisará de mecanismos contínuos que regulam, corrigem e normalizam os modos de existência, além de orientar o modo como os indivíduos devem se relacionar com um determinado regime de verdades. A produção dessa sociedade normalizadora, na qual a tecnologia de poder está centrada na docilização dos corpos e regulação da vida, tende a qualificar, medir, avaliar, hierarquizar e patologizar com o âmbito de cura os sujeitos considerados desviantes. Essa essência é colocada como justificativa de uma normatividade que precisaria ser respeitada.

Georges Canguilhem (1990) nos chama a atenção para o perigo de associar normalidade com uma média estatística, ou um padrão de comportamento comumente encontrado na sociedade. Para o autor, a anomalia seria um desvio estatístico ao qual será atribuído um valor moral relacionado às deformidades nocivas - ou mesmo incompatíveis com a sociedade e com a vida. Entretanto, o autor destaca que anomalias são consequências da variação individual e das singularidades que impedem que dois seres possam ser exatamente iguais, e que isso não deve ser visto como patologia, já que a individualidade e a diferença são partes fundamentais da vida e da saúde. A limitação forçada do ser humano a uma forma única e invariável de ser, estar e existir é considerada perigosa, pois anula as singularidades e a variabilidade dos organismos, sua significação e poder de alcance.

Portanto, deveríamos pensar se, na medida em que os seres vivos se afastam do tipo específico, seriam eles anormais que estão colocando em perigo os padrões de comportamento já definidos, ou se estes seres na verdade não seriam inventores a caminho de novas formas de existir. Logo, podemos pensar que não existe uma forma que seja normal ou patológica em si, já que se faz necessário considerarmos o meio em que o sujeito vive e a melhor forma de adaptação encontrada que o permita desenvolver sua vida.

Mas o problema, nesse caso, consiste em saber dentro de que oscilações em torno de um valor médio puramente teórico os indivíduos serão considerados normais. Se é verdade que o corpo humano é, em certo sentido, produto da atividade social, não é absurdo supor que determinadas constâncias de certos traços, indicados por uma média, reflitam na verdade um jogo de forças que engendra um determinado campo teórico e político que institui determinadas formas de ser, perceber e viver no mundo.

Essa função normalizadora da ciência se faz, principalmente, através dos discursos, que, por terem uma legitimidade, produzem sujeitos e objetos, vítimas e algozes, bons e maus e outras categorias dicotômicas que atribuem ao sujeito uma essência e o analisa como um objeto estático. Essa produção de verdades não leva em consideração o entendimento do fenômeno como um processo, que deve questionar em quais circunstâncias e a partir do fruto de quais processos coletivos uma pessoa deve ser considerada como vítima, boa ou má, perigosa, louca e assim por diante. Isso ocorre no momento em que criar um objeto é necessariamente criar um sujeito pelo qual esse objeto ganha um sentido, função ou valor elementar. No caso do TEPT e de outros rótulos psiquiátricos, percebemos que os próprios sujeitos se tornam ativos colaboradores no processo de medicalização dos seus problemas, nos quais buscam especialistas (como os profissionais "psi") para darem sentido a sua experiência, de modo a se enquadrar em uma demanda normativa introjetada, que deve corresponder ativamente às expectativas da família, sociedade e etc.

Os discursos oriundos das falas competentes também se materializam em determinadas práticas e instrumentos que ratificarão no cotidiano uma determinada norma, uma noção de saúde e uma visão específica do que seria doença e anormalidade. Criar critérios de diagnóstico para alterações na saúde mental constitui um instrumento de trabalho de referência para os profissionais da saúde e para a sociedade. $\mathrm{O}$ uso dos critérios de diagnóstico padronizados, tais como o DSM, produz feitos de enquadramento e esquadrinhamento de experiências singulares da existência humana. Isso ocorre na medida em que se acredita em um sujeito universal e em um modelo único do que deva ser considerado como saúde, onde as diversas formas de se relacionar com um evento estressante podem ser mensuradas, classificadas e diagnosticadas, e caso não possam, serão enquadradas e ajustadas - custe o que custar - nas condições já existentes.

Os manuais de diagnósticos, em sua criação, têm por objetivo a classificação dos sujeitos para estudos comparativos, propostas de intervenção e a implementação de políticas públicas na área da saúde que possibilitem qualidade de vida e maior atenção aos usuários de saúde mental. Portanto, faz-se necessário pensar nos limites em que angústias e outras formas de sofrimento se tornam padronizadas e patologizadas a partir de critérios únicos de diagnóstico. Não se trata examiná-los apenas sob o aspecto de uma norma 
a ser fixada, mas também se faz necessário colocar em análise os procedimentos de sujeição que põem em prática. Dessa forma, os diversos profissionais de saúde mental precisam rever e problematizar as atuais definições do que seria normal e patológico, além de produzir reflexões sobre a medicalização da vida e descontextualização dos sintomas de seu campo social, para que assim não se tornem reféns de um jogo capitalista que anula as singularidades da vida em prol de lucros financeiros, políticos e econômicos.

\section{A vitimização e o estado penal: é preciso defender a sociedade?}

Durante a Assembleia Geral das Nações Unidas realizada no Congresso de Prevenção de Crime e Tratamento de Delinquente em Milão, Itália, em 1985, a palavra vítima ganhou uma nova conceituação. A partir desse evento, foi criada a Declaração dos Princípios Básicos de Justiça para as Vítimas de Delitos e Abuso de Poder, em que o conceito de vítima se estendeu de casos que se referem à infração da norma penal e passou a também considerar pessoas em situações em que os princípios dos direitos humanos são violados (Kosovski, 2004). Tal visão representa um avanço na luta pela igualdade de direitos e uma ressignificação do conceito de vítima. A partir de então, o conceito de vítima não se restringe apenas ao direito penal, mas também passou a incluir casos de omissões, tortura e negligência, seja realizado por uma pessoa física, um grupo ou até mesmo o estado.

Partindo dessa perspectiva, entende-se que o processo de vitimização precisa ser historicamente e socialmente contextualizado, levando em consideração fatores físicos, psíquicos, sociais, econômicos e políticos, além do ambiente natural no qual o sujeito estava inserido. Sá (2004) chama a atenção aos processos de vitimização subjetiva, ao qual se inicia a partir da difusão social de um medo exacerbado e não compatível com a realidade que o circunda. Nesse contexto, o sujeito apresenta uma visão irracional e abstrata da violência, ao qual o subjetiva na figura da vítima sem que ocorra uma ofensa real e/ou objetiva.

Dessa forma, Sá (2004) aponta que as pessoas podem apresentar características vitimógenas que as tornam mais suscetíveis a se tornarem vítimas de crimes. Logo, se faz necessário analisar minuciosamente o processo de vitimização, visto que esse pode ser engendrado por um conjunto de interesses, ideologias e motivações conscientes e inconscientes não apenas por parte do agressor, mas também por parte de quem sofre a ação, que durante o evento pode apresentar não apenas uma complementaridade, mas também uma alternância de papéis no que diz respeito aos lugares instituídos de vítima e algoz.

De acordo com Fassin e Rechtman (2009), a leitura da violência sob a ótica do trauma deve ter a cautela de não compreender o objeto de investigação como estático, de tal modo que as vítimas não devam ser vistas como sujeitos meramente passivos. Os autores ilustram diversos usos, apropriações e benefícios do lugar social conferido a vítimas, onde as políticas de reparação, testemunha e produção de provas utilizam do artifício médico do diagnóstico de estresse pós-traumático em cunho mais político e econômico na busca por determinados direitos e interesses específicos do que necessariamente conferir o diagnóstico para avaliação e promoção da saúde do sujeito em si. Compreende-se que o estudo do trauma está ancorado na economia moral de nossa sociedade, que representa uma variedade de preocupações, valores e expectativas que estão presentes no contemporâneo. Os autores trazem como analisadores diversos casos que nos fazem pensar na revolução ideológica promovida pela introdução do conceito de trauma no campo da psicopatologia, tais como alteração do status do soldado ferido da guerra que passa a reivindicar seus direitos, mesmo com os inúmeros crimes e assassinatos cometidos; da pessoa que alega ter sofrido abuso sexual para obter o reconhecimento legal de seu sofrimento com base apenas em sua palavra; das vítimas de acidentes industriais que se apoiarem nos relatos de especialistas em vitimologia, usando o argumento de que foram traumatizados, para obter pagamentos de seguros; os habitantes de territórios palestinos, que usaram os relatos de psiquiatras humanitários para indicar que foram traumatizados com intuito de sensibilizar a opinião pública a seu favor na disputa por território, entre outros.

Já a vitimização e o diagnóstico de TEPT daqueles acometidos pela violência urbana precisam ser pensados com cautela, pois, além dos efeitos ético-políticos na sociedade e na vida do indivíduo, o diagnóstico de Estresse Pós-Traumático não é consensual e sua existência ainda é bastante controversa na literatura. Spitzer, First e Wakefield (2007) apontam para diferenças importantes no diagnóstico de TEPT entre o DSM-IV e o CID-10, aos quais o entorpecimento emocional que é considerado um elemento chave para o diagnóstico segundo o DSM-IV não é considerado relevante no CID-10, indicando que pessoas podem ser diagnosticadas com Transtorno de Estresse Pós-Traumático a partir de diferentes critérios. Outro problema que os autores também apontam se refere a alguns sintomas do TEPT (tais como irritabilidade, dificuldade de concentração, insônia, perda de interesse nas atividades cotidianas), 
que não são exclusivos dessa patologia e podem ser confundidos clinicamente com outros transtornos (tais como depressão) podendo gerar diagnósticos diferenciados. Um aspecto da nosologia do TEPT que também é bastante controverso foi apontado por McHugh e Treisman (2007) e se refere ao limiar em que determinadas respostas (tais como ansiedade, evitação e pesadelos) podem ser consideradas como reações comuns a um evento negativo, e não uma patologia em si.

A discussão sobre a necessidade do aprimoramento de pesquisas em torno das vítimas da violência e dos critérios de diagnóstico do Transtorno de Estresse PósTraumático está presente há décadas nas instituições acadêmicas. Entretanto, tais discussões nem sempre colocam como questão o impacto dos estudos na compreensão da criminalidade e formulação de políticas públicas de segurança no país. Tais estudos, ao estimarem as taxas de crimes, trazerem informações sobre áreas de risco, identificarem grupos mais vulneráveis, investigarem os efeitos da violência na saúde física e mental, estimarem a frequência dos pequenos crimes cometidos no cotidiano, entre outros, produzem uma visão própria do fenômeno da violência e da insegurança.

Outro fator em análise se refere a pesquisas que tipificam as características do(a) agressor(a) reportado pela vítima em um determinado tipo de crime, em que tais relatos poderão servir como instrumento do trabalho policial, delimitação da intervenção em locais considerados de risco, bem como propiciar o perfil específico do infrator, e, por seguinte, produzir processos de estigmatização e mecanismos formais e informais de controle da população em nome da manutenção da ordem pública.

Adaptando-se ao receituário neoliberal, as políticas de segurança se pautam em uma ideologia da segurança urbana no qual a periculosidade do "inimigo" não apenas provém das camadas mais pauperizadas da sociedade, mas apresenta uma cor e uma faixa etária bem definida. Prisão e aumento policial nas ruas são utilizadas como ferramentas para combater o inimigo interno e, por conseguinte, acabar com aquilo com que os meios de comunicação e outros agentes sociais rotulam como espaços violentos e de "plena barbárie". No entanto, pouco se discute sobre os efeitos que as políticas neoliberais produzem em nossa sociedade, tais como desemprego e a produção da miséria. Dessa forma, "um dos principais efeitos do capitalismo na atualidade é a produção de um grande contingente de pessoas que se encontram em um processo de marginalização, com pouca ou nenhuma possibilidade de integrar-se ao mundo de produção e consumo" (Zamora, Carnero, Pfeil, \& Ramalho, 2010, p. 154).
Assim, pautadas nos mecanismos de segurança, observam-se medidas drásticas de repressão e controle contra determinadas camadas da população. A ação disciplinar atende a interesses de grupos específicos, que buscam a implementação de medidas mais severas contra os "criminosos", que entre outras razões as utilizam como meio de se desviar a atenção dos verdadeiros problemas sociais, tais como má distribuição de renda, dificuldades em acesso a educação, saúde e moradia.

As atuais medidas de combate à violência concentram-se nas condições e efeitos do delito, tais como a medicalização da vítima, a busca de um perfil do agressor e pacificação dos locais considerados "de risco". Essas ações não consideram os impactos provenientes das condições extremamente adversas e injustas da sociedade (tais como a má distribuição de renda, elevadas taxas de desemprego e pobreza) na produção de vidas segregadas e acesso aos bens materiais, à saúde, à educação e às condições mínimas para que as pessoas possam ter uma vida digna.

Nesse contexto, vislumbra-se o surgimento de setores da população que se tornam socialmente mais vulneráveis, que personificarão a ideia de um inimigo interno, que será culpado por todos os males sociais, que ameaçarão a segurança e o bem-estar daqueles considerados como "cidadãos de bem". Sob o enunciado da "proteção" e pelo clamor pelo aumento da segurança, podemos observar a materialização de medidas extremamente violentas e repressivas em nossa sociedade, tais como encarceramento massivo, estigmatização penal, aumento do número de prisões, encarceramento de crianças (redução da maioridade penal), ações de "limpeza social" contra vendedores ambulantes, flanelinhas, prostitutas, moradores de rua, e de todos que fogem da normativa social.

Foucault (2005), em obra intitulada Em Defesa da Sociedade, ressalta o caráter binário da sociedade, onde há duas categorias de indivíduos, dois exércitos em confronto. As leis e a ordem social não significam uma pacificação, "a paz, na sua menor das engrenagens, faz surdamente a guerra" (Foucault, 2005, p. 61). Essa guerra não se faz entre dois grupos distantes, ou entre seres externos um ao outro, mas, pelo contrário, seria um enfrentamento de um único grupo que se desdobrou em dois. Essa lógica binária que incide sobre o corpo social se faz através de discursos que fazem uma raça aparecer como a verdadeira, a única, a detentora do poder, aquela que é titular da norma, contra aqueles que estão fora dela. Para aqueles que se encontram dentro do corpo social e fogem dos modelos instituídos resta representarem "consumidores falhos" da lógica instituída, que serão considerados perigosos à ordem 
social, sofrendo processos de eliminação, segregação, e posteriormente normalização. O autor nos chama a atenção para o surgimento de um racismo de Estado, um racismo que a sociedade vai exercer sobre si própria, contra alguns elementos, que ela mesma, em seu funcionamento, produziu.

O autor também nos chama a atenção para determinados processos de segregação em nossa sociedade, onde os mecanismos de poder, em dado momento, numa conjuntura precisa, produziram mecanismos de exclusão, vigilância e medicalização seja da loucura, da sexualidade ou da delinquência. Nesse contexto, o capitalismo não se interessa pelo louco, pelo infrator, pelo homossexual ou pela vítima da violência, mas se interessa pelos mecanismos que fixam esses sujeitos em determinadas técnicas de poder, aos quais poderão se tornar economicamente lucrativos e politicamente úteis. Um poder que não para de questionar, registrar, extrair saber a fins de controlar corpos e institucionalizar uma determinada norma. Afinal somos "julgados, condenados, classificados, obrigados a tarefas, destinados a uma certa maneira de viver ou a uma certa maneira de morrer, em função de discursos verdadeiros, que trazem consigo efeitos específicos de poder" (Foucault, 2005, p. 29). O sistema vai se interessar em como a exclusão social de determinada parte da população produz lucro econômico e utilidades políticas, que solidificam o sistema e o fazem funcionar em conjunto.

Dessa forma, o sistema não tem tanto interesse nas vítimas da violência, na punição dos delinquentes ou na reinserção deles, que não tem economicamente muito interesse. Em contrapartida, o conjunto das técnicas pelas quais as "vítimas" são controladas, subjetivadas e colocadas em evidência, resulta para o sistema, um interesse que funciona dentro de um jogo econômico-político geral. O que isso significa? Em certo sentido, significa um corte, uma cisão entre o que deve morrer e o que deve viver, o bom e o mal, quem é marginalizado do processo e quem recebe a tutela do Estado, ou seja, que a vida e a morte não são fenômenos naturais, mas também são produtos socialmente construídos e que estão inseridos dentro de um amplo campo político. No Biopoder é fazer viver e deixar morrer. Foucault (2005), assegura que o estado no biopoder tem essencialmente a função de incumbir-se com a vida, de organizá-la, regulamentar seus processos biológicos, de compensar as suas eventualidades, e a função da morte é legitimada no binarismo das raças, na cisão social e criação de dois grupos onde em nome da proteção de uns, legitima-se a morte dos outros.

Se entendemos que as maiores taxas de homicídio estão relacionadas às camadas mais pobres da população, que estatisticamente representam os homens jovens, negros e de baixa escolaridade, afirmar: "É preciso defender a sociedade" coloca-nos questões de qual sociedade estamos falando. Qual parcela precisa ser protegida? Até quando em nossas práticas ratificaremos binarismos, tais como entre bons e maus, normais e anormais, e não analisaremos os contextos em que esses conceitos foram produzidos? Precisamos defender o quê e de quem? Com quais finalidades? Onde? Como?

Acreditamos que os estudos de vitimologia também devem considerar as violações dos direitos humanos cometidos por cidadãos ou pelo Estado, tais como as vítimas de fome, vítimas de despejos forçados e coletivos, vítimas do desemprego, vítimas do racismo, vítimas de qualquer tipo de discriminação. É preciso pensar nas vítimas da falta de saúde pública, de escolas e assim por diante, ou seja, incluir todos os sujeitos de direitos que têm suas vidas violentadas de alguma forma. Precisamos pensar em novos mecanismos que auxiliem as pessoas que sofreram alguma forma de violência criando meios que as permitam participar das lutas em defesa do reconhecimento e respeito de seus direitos, de modo que possam desconstruir o papel passivo e tutelar que lhes foi atribuído, buscando fortalecer seus papéis de protagonistas de sua própria história.

\section{Considerações finais}

As constantes violações de direitos a que estão submetidas as pessoas que sofrem os impactos da violência vêm, já há algum tempo, gerando debates acerca da falta de mecanismos específicos de apoio na sua defesa e promoção de saúde. O termo vítima, que tem sua origem na área do direito e que recentemente foi apropriado pela medicina para caracterizar um determinado sofrimento mental, tem gerado consequências sociais que nos incitam a pensar nos mecanismos para prevenir a violência, e em como propiciar qualidade de vida e suporte a aqueles que sofrem o seu impacto.

O objetivo deste trabalho não visou a negar a existência de sofrimento e nem diminuir a importância dos estudos que investigam os impactos da violência na saúde mental, bem como suas formas de intervenção e tratamento. Mas buscou-se pensar nos limites e nos efeitos do papel social conferido às vítimas da violência. Além disso, buscou-se refletir sobre a criação de uma psicopatologia relacionada à vitimização, nesse caso o Transtorno de Estresse Pós-Traumático, ao qual mais do que caracterizar o objeto em si, pretendeu entender as práticas que o 
engendram, quais contingências históricas o fizeram emergir em um determinado momento e quais efeitos têm produzido atualmente na sociedade. $\mathrm{O}$ discurso aqui presente não visa a um efeito generalista ou mesmo supor uma falsa neutralidade, é um discurso de perspectiva, cujo objetivo buscou expor dissimetrias, pensar nos paradoxos e descentralizar certo discurso científico que fabrica sujeições em torno de uma anormalidade produzida.

A exposição a situações que representam risco de vida é um estressor marcadamente importante, devido às imagens grotescas e ao impacto emocional ocasionado pelos eventos inesperados associados com a morte. Investigar a incidência do TEPT na sociedade brasileira e sua relação com o fenômeno da violência requer uma análise bastante abrangente, que não se restrinja em mecanismos individualizantes do fenômeno e nem considere o social apenas como uma variável "ambiental" na produção de enfermidades.

$\mathrm{O}$ perigo em buscarmos os mecanismos subjacentes às vítimas de violência e associálas levianamente ao Transtorno de Estresse PósTraumático envolve a patologização daqueles que sofrem o impacto da violência em suas vidas, aos quais podemos, através de um processo de individualização de um fenômeno extremamente complexo, julgar as pessoas como "boas ou más", "fracas de caráter" ou portadoras de uma fragilidade, potencialmente estigmatizando-as. Também devemos considerar os efeitos políticos e o papel social dos processos de vitimização no desenvolvimento de políticas públicas, para que essas não se transformem em políticas de caráter repressivo, discriminatório e excludente, mas, ao invés disso, possam produzir políticas públicas de saúde, educação e segurança que possam contribuir na diminuição das desigualdades sociais e na redução da violência estrutural presentes na população brasileira.

Dessa forma, acreditamos que é preciso desconstruir a concepção internalizada de vítima ao qual muitas pessoas são subjetivamente colocadas, pela introjeção de doenças e incapacidades que lhe atribuem. Estigmas e papéis sociais, como a condição de vítima ou sua patologização, precisam também ser sócio-historicamente discutidos para se pensar os efeitos políticos que geram na sociedade.

Frente às opiniões aqui expressas, retornamos com o pensamento foucaultiano e indagamos: é preciso defender a sociedade? Anossa resposta é: sim. É preciso defender a sociedade, é preciso defender a vida. Isso vale sem dúvida se também nos deixarmos novamente invadir pelas reflexões de Georges Canguilhem e nos perguntarmos o que é a vida. A vida, segundo Canguilhem (1990), é o que admite a diversidade dos modos de existência, onde seja possível colocar constantemente em análise determinados regimes de verdades de forma a evidenciar que eles são sempre provisórios e locais. Trata-se de considerar os critérios de diagnóstico e as atuais políticas de vitimização, que nos orientam na forma de compreender as pessoas acometidas por situações de violência, como produções históricas, frutos do efeito de determinados discursos dentro de um contexto político.

Sendo as políticas de vitimização entendidas como produções sócio-históricas, dessa forma entendidas como não naturais, mas construídas, seria possível transformá-las? Produzir outras demandas sociais que não busquem ações patologizantes, coercitivas e de extermínio contra determinadas formas singulares de viver? Se nossas práticas produzem efeitos no mundo ao construírem objetos nos registros sociais, finalizamos o presente trabalho colocando a reflexão sobre como as nossas práticas podem propiciar políticas públicas que gerem novos rostos, novos territórios existenciais e novas formas de se relacionar com a diferença. Nesse sentido, afirmamos a VIDA como sendo atravessada pela ótica dos direitos humanos, podendo ser rotulada ou diagnosticada como um elemento ativo em todas as suas potencialidades, e que se encontra em um processo constante de devir em busca de novos caminhos, encontros e reformulações.

\section{Referências}

Andrade, L. H., Wang, Y., Andreoni, S., Silveira, C. M., Alemxadrino-Silva, C., Siu, E. R., Nishimura, R., Anthony, J. C., Gattaz, W. F., Kessler, R. C., \& Viana, M. C. (2012). Mental disorders in megacities: Findings from the São Paulo Megacity Mental Health Survey, Brazil. PLoS ONE, 7(2), $1-11$.

American Psychiatric Association. (1994). Diagnostic and Statistical Manual of Mental Disorders (4 ${ }^{\mathrm{a}}$ ed. rev.). Washington, DC: Author.

Boschen, M. J. (2008). Publication trends in individual anxiety disorders: 1980-2015. Journal of Anxiety Disorders, 22(3), 750-755.

Canguilhem, G. (1990). O normal e o patológico. Rio de Janeiro: Forense Universitária.

De Jong, K., Mulhern, M., Ford, N., Van der Kam, S., \& Kleber, R (2000). The trauma of war in Sierra Leone. Lancet, 1355(9220), 2067-2070.

Dugas, M. J., Anderson, K. G., Deschenes, S. S., \& Donegan, E. (2010). Generalized anxiety disorder publications: Where do we stand a decade later? Journal of Anxiety Disorders, 24(7), 780-784.

Fassin, D. \& Rechtman, R. (2009). The empire of trauma: Inquiry into the condition of victimhood. Princeton: Princeton University Press.

Foucault, M. (1988). Historia da sexualidade I. Rio de Janeiro: Graal.

Foucault, M. (2005). Em defesa da sociedade. São Paulo: Martins Fontes. 
Nórte, C. E. (2015). As vítimas da violência: entre discursos científicos e biopolíticas do contemporâneo.

Gaudenzi, P. \& Ortega, F. (2011). O estatuto da medicalização e as interpretações de Ivan Illich e Michel Foucault como ferramentas conceituais para o estudo da desmedicalização. Interface Comunicação, Saúde, Educação, 16(40), 21-34.

Kessler, R. C., Sonnega, A., Bromet, E., Hughes, M., \& Nelson, C. B. (1995). Posttraumatic Stress Disorder in the National Comorbidity Survey. Archives of General Psychiatry, 52(12), 1048-1060.

Kosovski, E. (2003). Drogas, violência e vitimização. In C. B. Leal \& P. H. Junior (Orgs.), A violência multifacetada: estudos sobre a violência e a segurança pública (pp. 169182). Belo Horizonte: Del Rey.

McFarlane, A. C. (2000). Posttraumatic stress disorder: A model of the longitudinal course and the role of risk factors. Journal of Clinical Psychiatry, 61( Suppl .5), 15-20.

McHugh, P. R. \& Treisman, G. (2007). PTSD: A problematic diagnostic category. Journal of Anxiety Disorders, 21(2), 211-222.

Reichenheim, M. E., Souza, E. R., Moraes, C. L., Jorge, M. H. P. M., Silva, C. M. F. P., \& Minayo, M. C. S. (2011). Violence and injuries in Brazil: The effect, progress made, and challenges ahead. Lancet, 1377(9782), 1984-1986.

Sá, A. A. (2004). Algumas considerações psicológicas sobre a vítima e a vitimização. In E. Séguin (Org.), Vitimologia no terceiro milênio (pp. 11-23). Rio de Janeiro: Forense.

Spitzer, R. L., First, M. B., \& Wakefield, J. C. (2007). Saving PTSD from itself in DSM-V. Journal of Anxiety Disorders, 21(2), 233-241.
Summerfield, D. (2001). The invention of post-traumatic stress disorder and the social usefulness of a psychiatric category. British Medical Journal, 322, 95-98.

Young, A. (1995). The harmony of illusions: Inventing post-traumatic stress disorder. Princetown: Princetown University Press.

Zamora, M. H., Carnero, V., Pfeil, F., \& Ramalho, J. (2010). Formação em psicologia e Segurança Pública. In C. E. Nórte, R. M. Macieira, \& A. L. L. Furtado (Orgs.), Formação: ética, política e subjetividades na Psicologia (pp. 80-95). Rio de Janeiro: Conselho Regional de Psicologia do Rio de Janeiro.

Submissão em: 13/01/2013

Revisão em: 29/05/2013

Aceite em: 26/06/2013

Carlos Eduardo Nórte é graduado em Psicologia pela Universidade Federal do Rio de Janeiro. Titulou-se mestre em Saúde Mental pelo programa de Pós-Graduação em

Psiquiatria e Saúde Mental da Universidade Federal do Rio de Janeiro. Endereço: Laboratório Integrado de Pesquisa sobre o Estresse (LINPES) - Av Venceslau Bras, 71 Fundos Urca - Instituto de Psiquiatria (IPUB/UFRJ), CIPE novo Prédio Leme Lopes - sala 6. Rio de Janeiro/RJ, Brasil. CEP 22290-140. E-mail: cadulsn@gmail.com 